\title{
Application of Minimalist Modern Concept in Bed and Family Rooms in Swiss-Bel Hotel, Nusa Dua Badung-Bali
}

\author{
I Made Dwi Prastiawan ${ }^{1}$, I Wayan Wiryawan ${ }^{2}$ \\ Bachelor Degree of Architecture Study Program \\ Faculty of Engineering-Udayana University \\ Jimbaran \\ dwikini@ymail.com \\ Architecture Study Program \\ Faculty of Engineering-Udayana University \\ Jimbaran
}

\begin{abstract}
In a hotel building a bedroom is the main facility that becomes the most important unit in a hotel building. In the design of the interior contained in the bedroom and living room owned by the Swiss-Bel hotel located in South Kuta District - Badung Regency using the application of the Modern Minimalist concept that can give the impression of luxury and simplicity in a design that is applied to the constituent elements such as material, furniture and colors used by the room so as to provide a maximum comfortable and peaceful atmosphere for guests who use it and display a strong modern minimalist concept in the room.
\end{abstract}

Index Terms - interior design, modern minimalist concept, bedroom, living room.

\section{INTRODUCTION}

In the elements contained in the building space of a hotel there are many types of rooms. In terms of functions can be grouped into three types of space functions, namely the main function, supporting functions and supporting functions. In the three groups of space functions certainly have their respective roles that are important to support all the activities that exist in the hotel. Each of these functions has a relationship with each other so that the activities that run at the hotel can take place smoothly, therefore the design of space in each function of the room must be considered properly for the convenience of visitors and hotel managers.

In the main function room group, there are types of rooms that have the most important role for hotel activities, namely sleeping rooms and family rooms that are common in a hotel room. The bedroom and family room as the main function of course must be highly considered in terms of interior layout for the comfort of visitors, a good inner space must pay attention to the comfort of visitors so that they are at home in a room, then they must pay attention to the privacy of the room and matters related to comfort for visitors such as ventilation, lighting and noise levels.

As a room that has the main function to rest and gather with family in a hotel room, the bedroom and family room should be able to give a comfortable impression for guests who will use the hotel room facilities. In an effort to create comfort for visitors who are active in it, it is necessary to design a concept of space that can give the impression of comfort and calm so that visitors can rest quickly and without interference from other visitors and hotel managers. In determining the concept of interior space, an approach to the characteristics of interior space is needed in terms of material, color and furniture used in hotel rooms. 


\section{RESUlt AND ANALISYS}

\section{A. Object Exsisting}

The first stage of the process of designing the inner space of the selected object is to carry out a review of the bedroom and family room objects that are housed in the Swiss-Bel Hotel. At the main facility in the form of a sleeping room in the Swiss-Bel Hotel is a deluxe room type bedroom that has facilities in the form of a bedroom, decorative table, work table, cupboard and decorations in the form of pots for indoor vegetation.

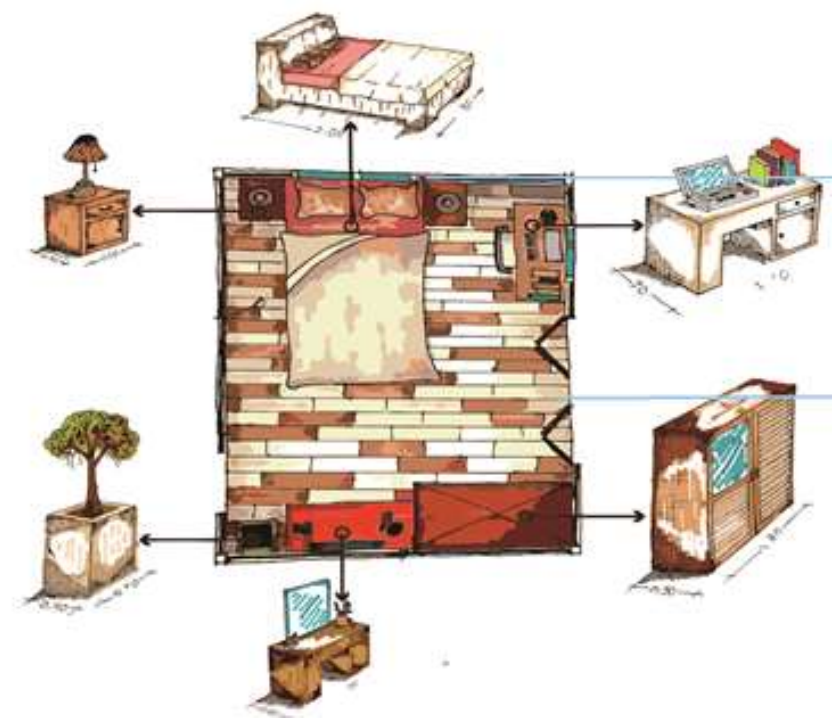

Fig. 1. Lay Out Object(source: Prastiawan)

The bed is placed close to the window so that visitors can feel the natural and cool air that enters into the room. There is an opening door leading to the balcony to the right of the bedroom as a facility for visitors to see the view outside the room and look for cool air.

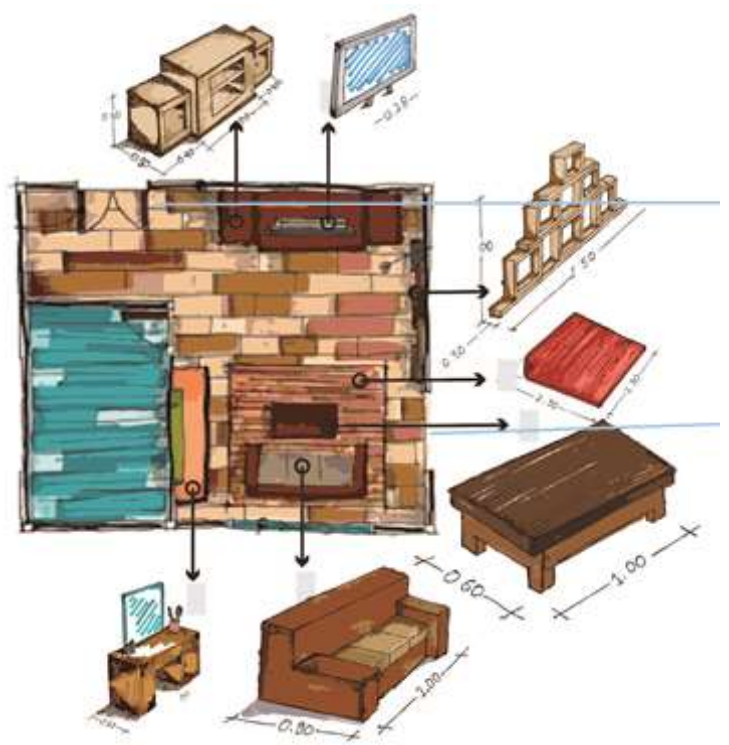

Fig. 2. Lay Out Object (source: Prastiawan)

In supporting facilities in the hotel room in the form of a family room has a room size that is quite spacious and the facilities provided are also quite complete and the design of the cozy living room and very suitable for relaxing when in a hotel room, facilities provided in the form of a sofa, television, tables and there are some wall decorations on the wall that have a mini-malis design and soothing the eyes, in addition to the living room area there is also a bathroom located next to each other so that it is easy to access by visitors if needed.

The entrance to the hotel room is located in the family room facing the bathroom and then to the family room and visitors are directed to the bedroom. The entrance to the bedroom is located to the right of the family room so that visitors can easily access the bedroom and the man-in room from the family room.

Based on the results of object reviews, Swiss-Bel Hotel has hotel rooms that apply the concept of a modern room and added a minimalist touch to the furniture as well as the colors and materials applied. Each room in the hotel room has a connection in terms of concepts and materials applied so that it has the same combination of rooms in the hotel room.

\section{B. Literature review}

Based on the review of existing objects in the previous stage, it can be concluded that the design concept applied in the design of the space in the bedroom and family room of the Swiss-Bel Hotel, Nusa Dua is a minimalist modern concept. This is based on the demands of comfort and aesthetics and the tranquility of visitors in the space. The application of color in the room is also considered given the color is the main focus in designing. Each color also has potential that has positive and negative effects on a person. The use of color is related to a person's psychological condition which will affect the body, mind, emotions and balance [1].

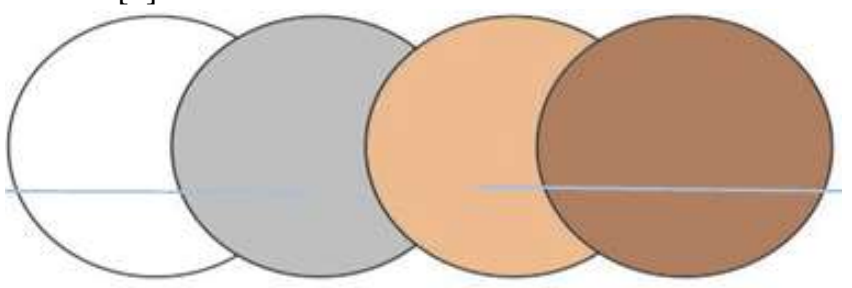

Fig. 3. Material and Color Samples Supporting Modern Natural Concepts (source: Prastiawan)

In the Modern Natural Concept, tonal colors are used such as brown which represents natural colors and simple colors such as gray, cream and white which represent modern impression which tends to look simple and not many motifs or patterns. In the application of the Natural Concept, natural materials such as wood which are given a clear finish can be applied so that the original texture remains visible and is not easily damaged. The effort to apply the Modern Concept is to use materials that are simple in character but still stylish and look clean [2].

\section{Application of Modern Natural Concepts}

In an effort to realize a misimalist modern concept that gives the impression of a simple but elegant material and 
furniture chosen that supports the appearance in accordance with the concept and selection of soft colors so as to give the impression of a cool eye and comfortable to look at, the lighting is also selected lamps that look minimalist that is down light and natural lighting sources obtained from the dominant wide openings in the room.

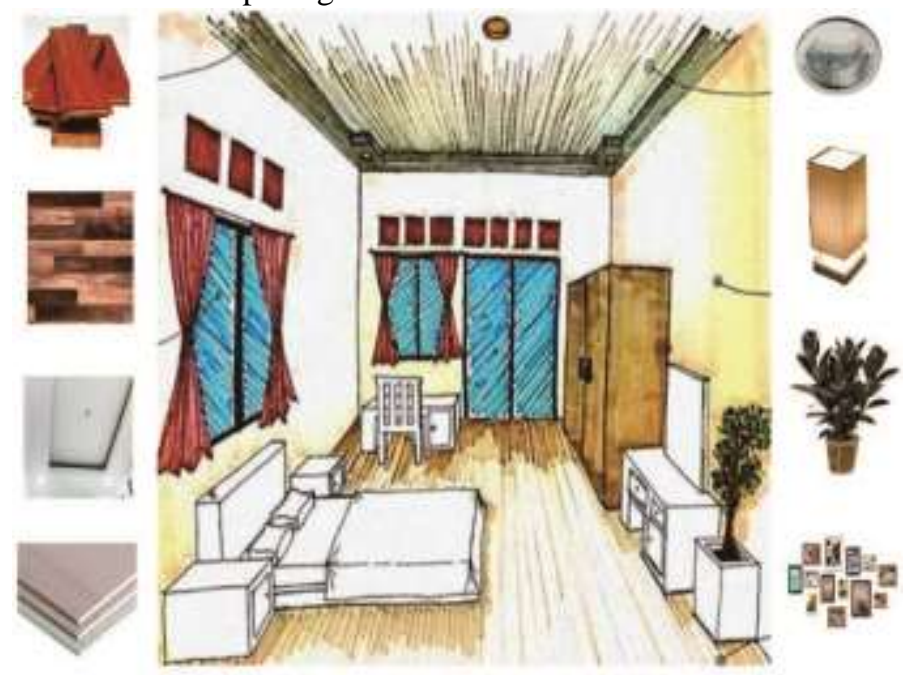

Fig. 4. Interior (source: Prastiawan)

In the bedroom space elements are applied to give the impression of a soft color to be seen as the color of ash, cream, brown and white and the selection of natural dominant materials such as wood in the windows, floors and selection of modern furniture and made from natural so as to strengthen minimalist impression on the Swiss-Bel Hotel's bedroom.

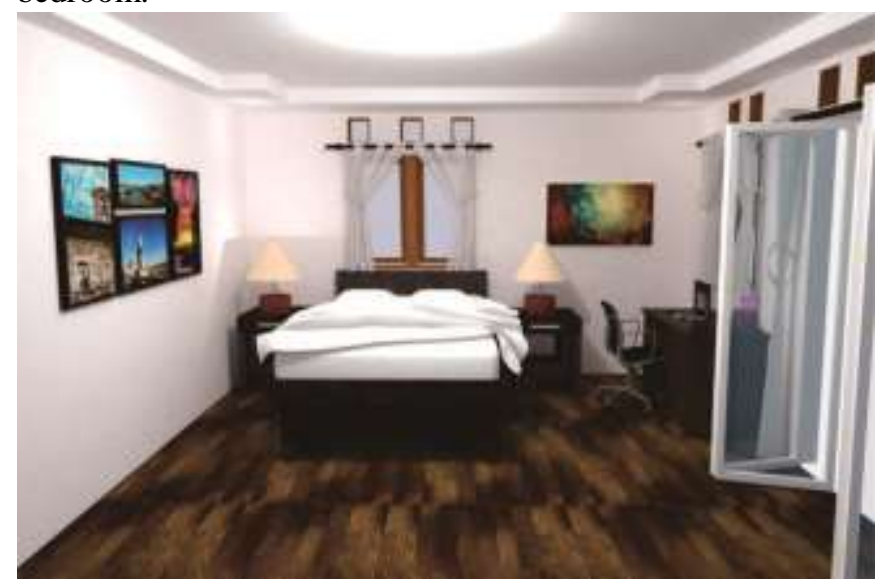

Fig. 5. Interior (source: Prastiawan)

The family room displays a modern impression in terms of furniture and minimalism in the room material section, and there are some vegetation in the pot to green the room and gives a cool natural impression so that visitors feel comfortable while in this room

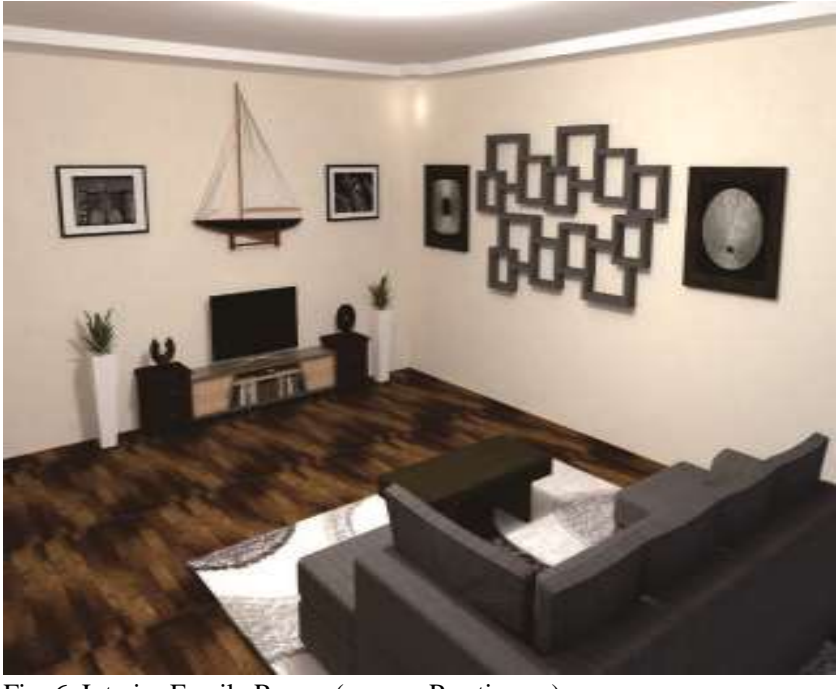

Fig. 6. Interior Family Room (source: Prastiawan)

\section{CONCLUSION}

Modern concepts that give the impression of luxury and minimalist concepts that give a simple impression when combined will produce a modern minimalist concept that gives the impression of luxury and simplicity at the same time so as to give the impression of a harmonious space. Like the application of these two concepts in the bedroom and family room of the Swiss-Bel Hotel, which gives the impression of luxury and comfort in a room.

\section{REFERENCES}

[1] Pile, John, "Color in Interior Design", USA : The McGraw- Hill Companies, 1997.

[2] Kurniawati, Novriyana \& Nanik, Rachamniyah, "Desain interior SPA Bernuansa Modern Natural Pada Pusat Kecantikan di Surabaya", Jurnal Teknik Pomits, 2012. 